\title{
Investigation of acute periradicular abscess videos from one virtual platform
}

\author{
Aline Nogueira de Andrade Uhl, ${ }^{1}$ Ana Paula Marques Paes da Silva, ${ }^{1}$ Alexandre Marques Paes da Silva, ${ }^{1}$ Lucio de Souza Gonçalves, ${ }^{1}$ Natan Mecler, ${ }^{2}$ Rodrigo \\ Carvalho de Souza, ${ }^{1}$ Dennis de Carvalho Ferreira ${ }^{1,3}$ \\ ${ }^{1}$ School of Dentistry, Estácio de Sá University, Rio de Janeiro, RJ, Brazil \\ ${ }^{2}$ School of Dentistry, Veiga de Almeida University, Rio de Janeiro, RJ, Brazil \\ ${ }^{3}$ School of Nursing, Rio de Janeiro State University, Rio de Janeiro, RJ, Brazil \\ - Conflicts of interest: none declared. \\ Abstract \\ Objective: to evaluate videos posted in the last ten years on YouTube ${ }^{\mathrm{TM}}$ virtual platform with the theme "acute periapical abscesses". Material and Methods: a \\ search was conducted in the YouTube ${ }^{\mathrm{TM}}$ video platform using the keywords "periapical abscess", "periradicular abscess", "apical alveolar abscess", "dental-alveolar apical \\ abscess", " suppurative periapical periodontitis" and "suppurative apical periodontitis" (Descriptors Science Health (DeCS)) and "oral abscess" and "mouth abscess" \\ (non-indexed). Once identified, their contents were evaluated, as well as their agreement with the literature, date of posting, number of views, duration, among others. \\ Results: 1,106 videos were identified, and 28 videos included in the final sample (inclusion and exclusion criteria). Of the excluded videos, $85.5 \%$ did not address the \\ topics to the terms sought. $78.6 \%$, were posted in 2017 and 2018, especially in the months of June and November. $64.3 \%$, exceeded two minutes, being the subject more \\ approached, the treatment of acute periradicular abscesses (75\%), followed by etiology $(50 \%)$ and symptoms (50\%). Conclusions: the internet is an important tool in \\ the dissemination of information in dentistry; however, the quality of this information should be reviewed by trained professionals. \\ Keywords: Abscess, Abscess in the mouth, Periapical abscess, Periradicular abscess, Internet.
}

\section{Introduction}

A cute periapical abscess is responsible for nearly $60 \%$ of dental emergencies, along with toothache. ${ }^{1}$ It is an inflammatory pathology that reaches the periradicular tissues as a consequence of an endodontic infection, also can occur from a periodontal infection. Typically, endodontic infection is the result of an extensive carious lesion or a trauma that generates a pulp exposure, which allows microorganisms to invade the root canal generating an inflammatory process that culminates with the necrosis of the pulp tissue, when these microorganisms or their products reach the periradicular region, either by the apical foramen, foramina or by perforations, ${ }^{3}$ can lead to two distinct inflammatory processes, one chronic and one acute. The chronic one occurs slowly and causes bone resorption that can be identified in the radiography as a radiolucent area, usually asymptomatic, and the acute process is accompanied by signs and symptoms such as pain, edema and trismus (in some cases), with formation of pus which leaves the dental element sensitive to percussion; ${ }^{4}$ and may be the exacerbation of the chronic process in $5 \%$ of cases per year. ${ }^{5,6}$

The exudate formed sometimes performs the cortical bone diffusing through the subcutaneous and submucosal spaces, ${ }^{7}$ and can be drained either by vestibular or palatine/ lingual of the affected tooth, in some cases of the upper teeth, reaching even the maxillary sinus or the nasal cavity. ${ }^{8}$

Anaerobic bacteria release endotoxins, exotoxins and proteolytic enzymes that degrade the tissue and stimulate an immune reaction with pus formation, in an attempt to defend the host from delimiting the infection, abscess formation can occur, where only anaerobic microorganisms survive. ${ }^{9}$

Despite being underestimated, the periapical abscess can lead to systemic complications when neglected or treated incorrectly, which can culminate in septicemia. Patient-related factors such as diabetes, malnutrition, alcoholism, smoking and use of illicit substances may increase the chances of morbidity and mortality. ${ }^{10}$ However, this event is rare; most cases can be resolved with antibiotic therapy. ${ }^{4}$

In cases where there is no response to antibiotics or there is no treatment for the infection, the periapical abscess may evolve and spread to regions of the head and/or neck, close to the involved tooth, and may lead to severe infection such as cellulitis - diffuse inflammatory process with pus formation, ${ }^{11,12}$ which threaten the patient's life either by sepsis or obstruction of the airways. ${ }^{13}$ The high occurrence of periradicular abscesses, and their serious complications, generates the need in the patients for the search for guidelines. For the most diverse reasons, there is not always the possibility of consulting with professionals to obtain information, which means that knowledge is acquired by alternative means. One of the most used means is the search on the internet due to the ease of access, in addition to specific websites; social networks are also sources of consultation. ${ }^{1,4}$

YouTube $^{\mathrm{TM}}$ is a platform that allows the sharing of videos both amateur and professional, reaching the mark of four billion views per day. ${ }^{14}$ It is the third most accessed website being surpassed only by the Facebook ${ }^{\circledR}$ and Google ${ }^{\circledR}{ }^{15}$ 
Content sought by Youtube ${ }^{\mathrm{TM}}$ users varies by age, habits and location, but it has been reported that more than $75 \%$ of people seek medical information ${ }^{16}$ and possibly the percentage of those seeking dental information is similar. ${ }^{17}$

YouTube $^{\mathrm{TM}}$ has been used as a viable database for research in the health sciences, with studies that performed qualitative analysis of present content as well as categories linked to the site, which involved medical topics such as anorexia, ${ }^{18}$ HIV infection, ${ }^{19}$ use of cigarettes ${ }^{20}$ first aid in burns, ${ }^{21}$ tonsillectomy, ${ }^{22}$ and dental such as oral cancer, ${ }^{23}$ fear and anxiety related to dental treatment, ${ }^{24}$ and endodontic treatment, ${ }^{15}$ however, no studies addressing endodontic origin infections in which periradicular abscesses are involved.

One research about endodontic treatment found that only $46 \%$ of the 60 videos analyzed were shared by dentists or specialists. In addition, it reported that in all videos the information was not complete, lacking content in the six categories created as etiology, anatomy, symptoms, procedure, postoperative and prognosis. ${ }^{15}$

The objective of the present study was to evaluate videos on acute periapical abscesses available on YouTube ${ }^{\mathrm{TM}}$ over the last ten years through quantitative and qualitative analysis (categories, content and criteria of agreement with literature data) and their implications for health maintenance.

\section{Material and Methods}

First, there was a long and detailed online search to verify if there were no studies published in the English and Portuguese languages on the same theme. Accordingly, the following descriptors were defined: "periapical abscess", "periradicular abscess", "apical alveolar abscess", "apical dentoalveolar abscess", "suppurative periapical periodontitis" and "suppurative apical periodontitis". These were checked in the Descriptors in Health Sciences (DeCS) if they were indexed. In addition, non-indexed descriptors were used: "oral abscess" and "mouth abscess".

The search was carried out from November to December 2018, with the survey and analysis of the videos that occurred by a previously trained evaluator (specialist in endodontics and with more than two years of clinical experience), who performed their analysis independently and if it occurred There was doubt, there was discussion for consensus with another researcher doctoral student in endodontics with more than ten years of clinical experience. The videos were accessed respecting the criteria described below for the composition of the sampling. and also, the boolean operator "and" was used when grouped the descriptors used.

The sample composition of the videos obeyed the following inclusion criteria, which were adapted and modified from previously published articles its publication in the Portuguese language; exhibition and exhibition lasting up to four minutes; the call or title of the videos should refer to the previously selected descriptors; presence of posts in the last ten years. The exclusion criteria were: duplicate videos; videos that are not related to the theme; presence of advertising and personal material; videos without sound or titles and diminished quality. All search videos from grouped key words were viewed in Portuguese language. ${ }^{23,25}$

The videos links were tabulated for analysis and presented in the results section for categories and identified content. All selected videos have been documented through tables and frequency distribution and presented at the end of the search where your information has records such as: number of videos per post year, number of views, title, postdates $^{23,25}$ and how the present content descriptions are identified in the posted videos.

Then, the videos were classified according to "criteria of agreement with literature data", and were classified as: total agreement (all data is in agreement with the descriptions available in the current literature), partial agreement (cited at least some data in agreement with the current literature) and those without concordance (those that contain content without scientific evidence or that diverge from current scientific evidence).

This study did not need to go through an research and ethics committee, as this was previously documented in the articles published in the international literature, ${ }^{19,23,25}$ including personal data, those from health professionals and virtual interactions with viewers of the videos were not analyzed in their content, they only entered the categorization as to the source. The content used has been considered in the public domain.

The results were tabulated in a database created in Microsoft Excel for Windows ${ }^{\circledR}$ software (Office 2010, Microsoft Corporation, USA) and were described in a descriptive way through tables with absolute and relative frequency distribution.

\section{Results}

After searching the Youtube ${ }^{\mathrm{TM}}$ page for keywords indexed in DeCS and non-indexed terms, a total of 1,106 results were found. The term that generated the most results was "mouth abscess", followed by "oral abscess". The indexed descriptors generated less results, the "apical dental-alveolar abscess" was the one that obtained the largest number of videos in this group, followed by "apical alveolar abscess", "periapical abscess" and "periradicular abscess". The terms "suppurative periapical periodontitis" and "suppurative apical periodontitis" generated very few results. The results of each search term are found in the Table 1.

With each access, the order of the videos presented itself in a different way. When keywords were enclosed in quotation marks (refining the search) the number of videos decreased to a total of 181, as shown in Table 1. The grou- 
ping of keywords generated 240 combinations, of which $152(63.33 \%)$ did not result in any video when the filter of less than four minutes was activated. Seven (2.92\%) of them generated results, but the videos did not meet the inclusion criteria.

Table 1. Overall result of the descriptors used in the online search, after the refinement of the search and with the application of the exclusion criteria.

\begin{tabular}{l|c|c}
\hline \multicolumn{1}{c|}{ Initial Search Term } & Results & $\%$ \\
\hline Periapical abscess & 306 & 27.67 \\
\hline Periradicular abscess & 297 & 26.85 \\
\hline Apical Alveolar Abscess & 316 & 28.57 \\
\hline Apical Dentoalveolar Abscess & 332 & 30.02 \\
\hline Periapical Suppurative Periodontitis & 18 & 1.63 \\
\hline Apical Suppurative Periodontitis & 11 & 0.99 \\
\hline Oral Abscess & 493 & 44.57 \\
\hline Abscess in the mouth & 530 & 47.92 \\
\hline \multicolumn{1}{c|}{ Search Term After Refinement } & Results & $\%$ \\
\hline Periapical abscess & 81 & 44.75 \\
\hline Periradicular abscess & 20 & 11.04 \\
\hline Apical Alveolar Abscess & 20 & 11.04 \\
\hline Apical Dentoalveolar Abscess & 60 & 33.14 \\
\hline Periapical Suppurative Periodontitis & 1 & 0.55 \\
\hline Apical Suppurative Periodontitis & 1 & 0.55 \\
\hline Oral Abscess & 20 & 11.04 \\
\hline Abscess in the mouth & 14 & 7.73 \\
\hline Diverse Subject & 946 & 85.53 \\
\hline Surgical procedure & 18 & 8.14 \\
\hline Foreign Language & & 1.63 \\
\hline Self-promotion & 18 & 1.63 \\
\hline
\end{tabular}

When the exclusion criteria were applied, only 28 videos were selected. Most of the deleted videos dealt with various subjects not related to the proposed theme or abscesses in other parts of the body, and even abscesses in animals. Some videos only exhibited surgical abscess drainage procedures without any information on the subject. Others were excluded because of the lack of sound or because they are self-promotion videos of professionals or clinics. A few videos in other languages also appeared, but were excluded, being Italian (1), English (8) and Spanish (9); a video in which the language is Portuguese Lusitanian was not excluded due to the possibility of understanding by the proximity with Brazilian Portuguese. The table below describes the number of videos by exclusion criteria.

The following are the selected videos and their number of views, which ranged from 12 to 7,661.744.
Although the initial study proposal was the survey for a period of ten years, the date of posting of the videos ranged from November 3, 2012 to November 19, 2018. The highest number of posts was 2017 and 2018.

Almost every month of the year had at least one video published in this period of four years, except for the month of March, with November 2017 being the month with the highest number of posts.

The duration of the videos ranged from 41 seconds to three minutes and 55 seconds. Most are longer than two minutes. The most discussed subject in the videos was treatment of the abscesses, followed by etiology and symptoms. Complications and prevention were also commented and only one video mentioned the microbiota involved (Table 2).

Only eleven of the evaluated videos (39.28\%) suggested to viewers the need for a dentist appointment for evaluation. Most of the videos are aimed at the lay public, however, three of them were addressed to dental professionals.

Concerning the criteria of agreement with the literature, partial agreement was the most frequent with 12 videos, total agreement was found in six of the videos and ten of them did not present any agreement.

Table 2. List of videos regarding the year of posting, duration and the subject addressed.

\begin{tabular}{l|c|c}
\hline \multicolumn{1}{c|}{ Post Year } & Number of videos & $\%$ \\
\hline 2012 & 1 & 3.57 \\
\hline 2015 & 3 & 10.71 \\
\hline 2016 & 2 & 7.14 \\
\hline 2017 & 11 & 39.29 \\
\hline 2018 & 11 & 39.29 \\
\hline \multicolumn{1}{c|}{ Duration } & 5 & $\%$ \\
\hline Up to 1 minute & 5 & 17.86 \\
\hline 1 minute-2 minutes & 9 & 17.86 \\
\hline 2 minutes- 3 minutes & 9 & 32.14 \\
\hline 3 minutes-4 minutes & 14 & 32.14 \\
\hline \multicolumn{1}{c|}{ Subjects } & 14 & $\%$ \\
\hline Treatments & 9 & 75.00 \\
\hline Etiology & 5 & 50.00 \\
\hline Symptoms & 1 & 50.00 \\
\hline Complications & & 32.14 \\
\hline Prevention & Number of videos & 17.85 \\
\hline Microbiota & 21 & \\
\hline
\end{tabular}

\section{Discussion}

According to some studies published in the current literature, the number of users who believe that the information contained in YouTube ${ }^{\mathrm{TM}}$ is true reaches $33 \%,{ }^{15}$ which leads health professionals to worry about the content that 
has been released, since videos with medical themes are the most wanted ${ }^{16,26}$ and methods of control over their veracity are required, which in general does not occur. ${ }^{15}$ In view of this need, the purpose of this study was to quantitatively and qualitatively evaluate videos shared on the YouTube ${ }^{\mathrm{TM}}$ platform with the theme of acute periradicular abscess, through search for descriptors.

Although a large number of results were presented in the search, few were the ones that really addressed the proposed theme (2.53\%), even though the term was limited to a specific region (mouth) there were suggestions of abscess videos in several regions of the human body, or it was the subject of a generic form.

When the terms were written in quotation marks, the number of results was reduced, restricting the number of videos that did not match the theme, but in some cases also hid videos of interest to the research.

The keywords used in the search were grouped initially from 2 to 2, and progressively, until a search with all together was made. This grouping generated 240 combinations. Out of this total, the majority (63.33\%) did not generate results with the message "No results found - Use different keywords or remove search filters," which may have been generated by the filter less than four minutes. Some combinations (2.92\%) resulted in videos that did not fit the inclusion criteria proposed by the present study. None of the combinations resulted in the total of 28 videos previously found in the individual search, which can be explained by the fact that the use of the "and" particle has a restrictive character, tapering the results, and also no new videos were added with the combined search, demonstrating that the individual search generated a broader result.

Most of the authors were laypeople (60.71\%) who generated content for laypeople, and only $39.28 \%$ of the videos stimulated consultation with a dentist for diagnosis and treatment, which justifies their concern about lack of control over information, ${ }^{27,28}$ and corroborates the need for dental professionals to work on this platform.

The most frequently discussed subject was treatment. Several forms of periradicular abscess were indicated, as indicated by the literature, drainage and, when necessary, antibiotic therapy, ${ }^{4}$ to the use of alternative methods ranging from consumption of teas, plants and herbs to rinse with warm water, salt water and sodium bicarbonate application, without any support in the literature. When the etiology was approached all the videos reported the involvement of microorganisms arising from carious lesions or dental trauma, which is in agreement with what has been, described ${ }^{3}$. Symptoms, such as local pain and edema were also described, but no videos were identified that referred to trismus or percussion sensitivity. ${ }^{4}$ A little over $30 \%$ of the results reported the possible complications of periradicular abscesses, ${ }^{10,29,30}$ the mentioned complications were Ludwig's angina, bacterial endocarditis, septicemia, cerebral abscess, meningitis, osteomyelitis, sinusitis, thrombosis of the cavernous sinus and mediastinitis, ${ }^{4}$ but of the eight videos that addressed the complications, five did not discriminate what they were. One of the videos presented oral abscess as the cause of death in pregnant women due to the possibility of septicemia. In a few cases (17.55\%), oral hygiene care was indicated as a form of prevention of the abscess with the intention of avoiding the appearance of carious lesions. ${ }^{3}$

When the contents of the videos were analyzed in agreement with the literature, $39.28 \%$ of the videos presented partial concordance, since it cited at least one data according to the literature, generally the microbial etiology. ${ }^{2,3}$ The percentage of non-compliant videos reached $25 \%$ of the total, which causes great concern when we remember that the majority of the audience is composed of lay people who do not have access or are unaware of the current scientific evidence, forms of treatment based on plants, teas and various oils, including the use of a clay poultice was suggested. The videos with total agreement totaled $35.72 \%$, in which all the information transmitted was in agreement with the literature, including sources of information such as: endodontic book, Ministry of Health manual and guideline of the American Association of Endodontists, which is a reference for endodontists around the world, which demonstrates how YouTube $^{\mathrm{TM}}$ can be used as a vehicle for the dissemination and popularization of science.

\section{Conclusion}

According to the present study, the number of videos related to the acute periradicular abscess in Portuguese is small and, for the most part, does not reproduce completely the guidelines of the current literature, which evidences the need for endodontic professionals to engage in the dissemination of scientifically based information.

\section{References}

1. Quinonez C, Gibson D, Jokovic A, Locker D. Emergency department visits for dental care of nontraumatic origin. Community Dent Oral Epidemiol. 2009;37(4):366 -371.

2. Torabinejad M, Shabahang S. Pulp and periapical pathosis. In Torabinejad M, Walton RE (ed). Endodontics. Principles and practice. 4 th ed. Saunders/Elsevier: St. Louis, MO; 2009. P. 49-67.

3. Sasaki H, Stashenko P. Interrelationship of the pulp and apical periodontitis.
In Hargreaves KM, Goodis HE, Tay FR (ed). Seltzer and Bender's dental pulp. Chicago, IL: Quintessence Publishing; 2012. P. 277-299.

4. Bertossi D, Barone A, Iurlaro A, Marconcini S, De Santis D, Finotti M et al. Odontogenic Orofacial Infections. J Craniofac Surg. 2017;28(1):197-202.

5. Eriksen HM. Epidemiology of apical periodontitis. In: Orstavik D, Pitt Ford T (eds). Essential endodontology. 2nd ed. Oxford, UK: Blackwell Science Ltd; 2008. P. 262-274. 
6. Baumgartner JC. Microbiologic aspects of endodontic infections. J Calif Dent Assoc. 2004;32(6):459-468.

7. Gill Y, Scully C. Orofacial odontogenic infections: review of microbiology and current treatment. Oral Surg Oral Med Oral Pathol. 1990;70(2):155-158.

8. Siqueira JF, Rôças IN. Microbiology and Treatment of Acute Apical Abscesses. Clin Microbiol Rev. 2013;26(2):255-273.

9. Robertson D, Smith A. The microbiology of the acute dental abscess. J Med Microbiol. 2009;58(Pt2):155-162.

10. Daramola OO, Flanagan CE, Maisel RH, Odland RM. Diagnosis and treatment of deep neck space abscesses. Otolaryngol Head Neck Surg. 2009;141(1):123-130. 11. Levi ME, Eusterman VD. Oral infections and antibiotic therapy. Otolaryngol Clin N Am. 2011;44(1):57-78.

12. Baumgartner JC, Siqueira JFJr, Sedgley CM, Kishen A. Microbiology of endodontic disease. In: Ingle JI, Bakland LK, Baumgartner JC (eds). Ingle's endodontics 6th ed. BC Decker: Hamilton, Canada; 2008. p221-308.

13. Baqain ZH, Newman L, Hyde N. How serious are oral infections? J Laryngol Otol. 2004;118(7):561-565.

14. Pring C. 100 social media statistics for 2012. The Social Skinny. 2012. Disponível em: http://thesocialskinny.com/100-social-media-statistics-for-2012/

15. Nason K, Donnelly A, Duncan HF. YouTube as a patient-information source for root canal treatment. Int Endod J. 2015;49(12):1194-1200.

16. Lee JS, Seo HS, Hong TH. YouTube as a source of patient information on gallstone disease. World J Gastroenterol. 2014;20(14):4066-70.

17. Parsons CF, Breckons M, Durham J. Twitter: a viable medium for daily pain diaries in chronic orofacial pain? Br Dent J. 2015;219(2):75-8.

18. Syed-Abdul S, Fernandez-Luque L, Jian WS, Li YC, Crain S, Hsu MH et al. Misleading health-related information promoted through video-based social media: anorexia on YouTube. J Med Internet Res 2013;13;15(2):e30.

19. Silva ES da, Pimenta SR, Silva AMP, Tavares JMAB, Broca PV, Montenegro HRA, et al. Análise de vídeos sobre HIV/AIDS e adolescência. Rev Enferm UFPE online. 2018;12(11):3046-51.

20. Carroll MV, Shensa A, Primack B. A comparison of cigarette- and hookah-related videos on YouTube. Tob Control. 2013;22(5):319-23.

21. Butler DP, Perry F, Shah Z, Leon-Villapalos J. The quality of video information on burn first aid available on YouTube. Burns. 2013;39(5):856-9.

22. Strychowsky JE, Nayan S, Farrokhyar F, MacLean J. You-Tube: a good source of information on pediatric tonsillectomy? Int J Pediatr Otorhinolaryngol. 2013;77(6):972-5.

23. Hassona Y, Taimeh D, Marahleh A, Scully C. YouTube as a source of information on mouth (oral) câncer. Oral Dis. 2016;22(3):202-208.

24. Gao X, Hamzah SH, Yiu CK, McGrath C, King NM. Dental fear and anxiety in children and adolescents: qualitative study using YouTube. J Med Internet Res. 2013;22;15(2):e29.

25. Carvalho JA de, Gurgel PKF, Lima KYN de, Dantas CN, Martins CCF. Análise de vídeos do YouTube ${ }^{\circledR}$ sobre aleitamento materno: importância e benefício. Rev enferm UFPE on line. 2013;7(esp):1016-22.

26. Boston MM, Ruwe E, Duggins A, Willging P. Internet use by parents of children undergoing outpatient otolaryngology. Arch Otolaryngol Head Neck Surg. 2005;131(8):719-22.

27. Nason GJ, Tareen F, Quinn F. Hydrocele on the web: an evaluation of internet based information. Scand J Urol. 2013;47(2):152-7.

28. Griffiths L. Uh oh: my email was misinterpreted. What now? At: www.zenlegalnetworking.com/2010/07/articles/law-firm-client-service/uh-ohmyemail-was-misinter-preted-what-now/.

29. Huang TT, Tseng FY, Liu TC, Hsu CJ, Chen YS. Deep neck infection in diabetic patients: comparison of clinical picture and outcomes with nondiabetic patients. Otolaryngol Head Neck Surg. 2005;132(6):943-947.

30. Tung-Yiu W, Jehn-Shyun H, Ching-Hung C, Hung-An C. Cervical necrotizing fasciitis of odontogenic origin: a report of 11 cases. J Oral Maxillofac Surg. 2000;58(12):1347-1352.

\section{Mini Curriculum and Author's Contribution}

1. Aline Nogueira de Andrade Uhl - DDS; MSc. Contribution: Effective scientific and intellectual participation for the study; data interpretation; preparation and draft of the manuscript; critical review and final approval: ORCID: 0000-0001-6158-751X

2. Ana Paula Marques Paes da Silva - DDS; MSc student. Contribution: Effective scientific and intellectual participation for the study; preparation and draft of the manuscript; final approval: ORCID: 0000-0001-8243-6761

3. Alexandre Marques Paes da Silva - DDS; PhD student. Contribution: Effective scientific and intellectual participation for the study; data acquisition, data interpretation; preparation and draft of the manuscript; critical review and final approval: ORCID: 0000-0001-7559-2555

4. Lucio de Souza Gonçalves - DDS; PhD. Contribution: Data interpretation; preparation and draft of the manuscript; critical review and final approval: ORCID: 0000-0002-4388-6310

5. Natan Mecler - DDS; MSc student. Contribution: Effective scientific and intellectual participation for the study; critical review and final approval: ORCID: 00000002-5065-530X

6. Rodrigo Carvalho de Souza - DDS; PhD. Contribution: Effective scientific and intellectual participation for the study; critical review and final approval: ORCID: 0000-0002-1887-289X

7. Dennis de Carvalho Ferreira - DDS; PhD. Contribution: Effective scientific and intellectual participation for the study, data interpretation; preparation and draft of the manuscript; critical review and final approval: ORCID: 0000-0003-4166-3284

Submitted: 09/17/2019 / Accepted for publication: 10/31/2019

Corresponding author

Alexandre Marques Paes da Silva

E-mail: xandemps@gmail.com 